\title{
Meiothermus cerbereus sp. nov., a New Slightly Thermophilic Species with High Levels of 3-Hydroxy Fatty Acids
}

\author{
ANA PAULA CHUNG, ${ }^{1}$ FRED RAINEY,${ }^{2} \dagger$ M. FERNANDA NOBRE, ${ }^{3} \mathrm{JUTTA}^{\mathrm{B}} \mathrm{BURGHARDT},{ }^{2}$ AND \\ MILTON S. DA COSTA ${ }^{1 *}$ \\ Departamento de Bioquímica ${ }^{1}$ and Departamento de Zoologia, ${ }^{3}$ Universidade de Coimbra, 3000 Coimbra, Portugal, \\ and Deutsche Sammlung von Mikroorganismen und Zellkulturen, 38124 Braunschweig, Germany ${ }^{2}$
}

\begin{abstract}
Strains of Meiothermus cerbereus sp. nov. were isolated from the hot springs within the Geysir geothermal area of Iceland. The strains of Meiothermus cerbereus produce red-orange-pigmented colonies, have an optimum growth temperature of about $55^{\circ} \mathrm{C}$, and have higher levels of 3-OH fatty acids than the strains of the other species of the genus Meiothermus. These strains, unlike all other strains of the species of the genus Meiothermus examined previously, require cysteine, thiosulfate, or thioglycolate for growth in liquid Thermus medium, but not in the corresponding medium solidified with agar. Several strains belonging to Meiothermus silvanus, isolated from Geysir, also required reduced sulfur compounds for growth in liquid medium, leading to the hypothesis that this requirement is not a taxonomic characteristic of the new species. The new species represented by strains GY-1 ${ }^{\mathrm{T}}$ and GY-5 can be distinguished from the other species of the genus Meiothermus by biochemical characteristics, fatty acid composition, DNA-DNA reassociation values, and 16S ribosomal DNA sequence. The type strain for Meiothermus cerbereus is GY-1 (= DSM 11376).
\end{abstract}

The recently described genus Meiothermus comprises the species Meiothermus chliarophilus, Meiothermus ruber, and Meiothermus silvanus (19). The species of this genus were formerly included in the genus Thermus and were generally referred to as the "low-temperature" species to distinguish them from the species with optimum growth temperatures of about $70^{\circ} \mathrm{C}(8,15,23,27,29,33)$. The species of the genus Meiothermus can be distinguished from the species of the genus Thermus by the lower optimum growth temperature range, the presence of moderate levels of $2-\mathrm{OH}$ fatty acids in the species of Meiothermus but not in the species of the genus Thermus, and about $14 \% 16 \mathrm{~S}$ ribosomal DNA (rDNA) sequence divergence between the two genera (19).

The strains of the species of the genus Meiothermus form red- or yellow-pigmented colonies, have a respiratory metabolism, have an optimum growth temperature ranging between 50 and $65^{\circ} \mathrm{C}$, and have been isolated from widely distributed hot springs or as contaminants in fermentors running at elevated temperatures $(8,21,23,29,33)$. Recently, we isolated several strains of the genus Meiothermus from the geothermal area at Geysir, Iceland; two red-pigmented strains were identified as Meiothermus silvanus, which had previously been isolated only from the hot spring at Vizela, Portugal (29), while six other red-orange-pigmented strains did not belong to any of the known species of the genus Meiothermus. On the basis of phenotypic and chemotaxonomic characteristics, DNA-DNA hybridization results, and $16 \mathrm{~S}$ rDNA sequence data, we describe a new species of the genus Meiothermus for which we propose the name Meiothermus cerbereus.

\section{MATERIALS AND METHODS}

Isolation and bacterial strains. Strains GY-1 ${ }^{\mathrm{T}}$, GY-2, GY-3, GY-4, GY-5, GY-6, GY-8, and GY-10 were isolated from hot springs located within the Geysir geothermal area in Iceland. Water samples were transported without tempera-

\footnotetext{
* Corresponding author. Mailing address: Departamento de Bioquímica, Universidade de Coimbra, Apartado 3126, 3000 Coimbra, Portugal. Phone: 351-39-24024. Fax: 351-39-26798. E-mail: milton @cygnus.ci.uc.pt.

$\dagger$ Present address: Department of Microbiology, Louisiana State University, Baton Rouge, LA 70803.
}

ture control and filtered 3 days later through membrane filters (Gelman type GN-6; pore size, $0.45 \mu \mathrm{m}$; diameter, $47 \mathrm{~mm}$ ); the filters were placed on the surface of Thermus agar plates (33), and these preparations were wrapped in plastic bags and incubated at $50^{\circ} \mathrm{C}$ for up to 7 days. Cultures were purified by subculturing and were kept at $-80^{\circ} \mathrm{C}$ in Thermus medium containing $15 \%$ glycerol.

Several strains of the species of the genus Meiothermus were used for comparative purposes. The type strain of Meiothermus ruber (= DSM $1279^{\mathrm{T}}$ ) was obtained from the Deutsche Sammlung von Mikroorganismen und Zellkulturen, Braunschweig, Germany; Meiothermus ruber strains 16105 and 16106 were isolated from hot springs at Hveragerdi, Iceland, and kindly provided by R. Sharp (Centre for Applied Microbiology and Research, Salisbury, United Kingdom); Meiothermus chliarophilus ALT-8 (= DSM 9957 $)$ and Meiothermus silvanus VI-R2 ( = DSM $9946^{\mathrm{T}}$ ) were our isolates.

Morphological, biochemical, and tolerance characteristics. Cell morphology and motility were examined by phase-contrast microscopy during the exponential growth phase in Thermus medium. Cell dimensions were determined with an ocular micrometer calibrated with a stage micrometer. Catalase activity was determined by the formation of bubbles with a $3 \%$ hydrogen peroxide solution; oxidase activity was determined by the oxidation of $1 \%$ aqueous tetramethyl- $p$ phenylenediamine on filter paper at room temperature. The presence of spores was determined after 7 days of growth on Thermus medium without tryptone, to which $10 \mathrm{~g}$ of soluble starch per liter was added. Unless otherwise stated, all biochemical and tolerance tests were performed as described previously $(17,25)$ with Thermus liquid medium or Thermus agar, both containing sodium thiosulfate $\left(0.1 \mathrm{~g} \mathrm{liter}^{-1}\right)$, at $50^{\circ} \mathrm{C}$ for up 5 days. The growth temperature range of strains GY-1 ${ }^{\mathrm{T}}$, GY -5 , and GY-8 and the type strains of Meiothermus ruber, Meiothermus silvanus, and Meiothermus chliarophilus was examined by measuring the turbidity $(660 \mathrm{~nm})$ of cultures incubated in 300-ml metal-cap Erlenmeyer flasks containing $100 \mathrm{ml}$ of Thermus medium with $\mathrm{Na}_{2} \mathrm{~S}_{2} \mathrm{O}_{3}$ in a reciprocal water bath shaker. The $\mathrm{pH}$ range for growth was examined at $55^{\circ} \mathrm{C}$ in the same medium with $30 \mathrm{mM}$ MES [2-( $N$-morpholino $)$ ethanesulfonic acid] for $\mathrm{pH}$ values between 5.0 and $6.5,30 \mathrm{mM}$ Tris for $\mathrm{pH}$ values between 7.0 and 8.5 , and $30 \mathrm{mM}$ CAPSO [3-(cyclohexylamino)-2-hydroxy-1-propanesulfonic acid] for $\mathrm{pH}$ values between 9.0 and 10.5; the $\mathrm{pH}$ of each buffer was adjusted with $\mathrm{HCl}$ or $\mathrm{NaOH}$. The $\mathrm{pH}$ values were determined at room temperature. Control media containing each buffer adjusted to $\mathrm{pH} 8.2$ were used to assess possible inhibitory effects of the buffering agents.

Single-carbon-source assimilation tests were performed with a minimal medium composed of Thermus basal salts with yeast extract $\left(0.1 \mathrm{~g} \mathrm{liter}^{-1}\right)$ and without nitrate, to which filter-sterilized ammonium sulfate $\left(0.5 \mathrm{~g} \mathrm{liter}^{-1}\right)$, $\mathrm{Na}_{2} \mathrm{~S}_{2} \mathrm{O}_{3}\left(0.1 \mathrm{~g} \mathrm{liter}^{-1}\right)$, and the carbon sources $\left(2.0 \mathrm{~g} \mathrm{liter}^{-1}\right)$ were added. Growth was examined daily by measuring the turbidity of cultures incubated at 50 or $55^{\circ} \mathrm{C}$ in $20-\mathrm{ml}$ screw-cap tubes containing $10 \mathrm{ml}$ of medium for 7 days. Positive and negative control cultures were grown in Thermus medium and in minimal medium containing $\mathrm{Na}_{2} \mathrm{~S}_{2} \mathrm{O}_{3}$, but without a carbon source.

Determination of thiosulfate and sulfate in the growth medium. Strain GY -5 was grown at $55^{\circ} \mathrm{C}$, and the type strain of $M$. ruber was grown at $60^{\circ} \mathrm{C}$ in Thermus medium lacking sulfate, to which filter-sterilized sodium thiosulfate was added to give a final concentration of approximately 0.1 or $1.0 \mathrm{~g} \mathrm{liter}^{-1}$. At appropriate intervals, the cultures were harvested and filtered through Gelman type GN-6 
membrane filters. The levels of thiosulfate and sulfate in the filtrates were determined by the methods described by Westley (32) and Sörbo (28), respectively.

Polar lipid, lipoquinone, and fatty acid composition. The cultures used for polar lipid and lipoquinone analyses were grown on Thermus agar medium at a temperature of $50^{\circ} \mathrm{C}$ for $48 \mathrm{~h}$. The cells were removed from the surface of the petri dishes, and the extraction of lipids was performed as described previously (31). The individual polar lipids were separated by single-dimensional thin-layer chromatography (TLC) on silica gel G plates ( 0.25 -mm thickness; Merck) with a solvent system consisting of chloroform, methanol, acetic acid, and water (80: $12: 15: 4$, by volume).

Lipoquinones were extracted from freeze-dried cells and purified by TLC as described by Tindall (30). The lipoquinones were separated with a Gilson highperformance liquid chromatography apparatus by using a reverse-phase column (RP18; Spherisorb, S5 ODS2) with methanol-heptane $(10: 2$, by volume) as the mobile phase and were detected at $269 \mathrm{~nm}$

Cultures for fatty acid analysis were grown on Thermus medium plates, with and without thiosulfate, in sealed plastic bags submerged in a water bath at $50^{\circ} \mathrm{C}$ for $48 \mathrm{~h}$. Fatty acid methyl esters (FAMEs) were obtained from fresh wet biomass by saponification, methylation, and extraction as described previously (14). The FAMEs were separated with a Hewlett-Packard model 5890 gas chromatograph equipped with a flame ionization detector fitted with a $5 \%$ phenylmethyl silicone capillary column $(0.2 \mathrm{~mm}$ by $25 \mathrm{~m}$; Hewlett-Packard). The carrier gas was high-purity $\mathrm{H}_{2}$, the column head pressure was $60 \mathrm{kPa}$, the septum purge was $5 \mathrm{ml} \mathrm{min}-1$, the split ratio was $55: 1$, and the injection port temperature was $300^{\circ} \mathrm{C}$. The temperature of the oven was programmed from 170 to $270^{\circ} \mathrm{C}$ at a rate of $5^{\circ} \mathrm{C} \mathrm{min}-1$. Identification and quantification of the FAMEs, as well as the numerical analysis of the fatty acid profiles, were performed by using the standard MIS Library Generation Software (Microbial ID Inc., Newark, Del.)

Determination of $\mathbf{G}+\mathbf{C}$ content of DNA and DNA-DNA reassociation studies. The DNA was isolated as described by Cashion et al. (3). The $G+C$ content of DNA was determined by high-performance liquid chromatography as described by Mesbah et al. (18). DNA for DNA-DNA reassociation studies was isolated by chromatography on hydroxyapatite by the procedure of Cashion et al. (3). DNADNA hybridization was carried out as described by De Ley et al. (5), with the modifications described by $\mathrm{Hu} 3$ et al. (10), with a Gilford System model 2600 spectrophotometer equipped with a Gilford model 2527-R thermoprogrammer and plotter. Renaturation rates were computed with the TRANSFER:BAS program (11).

$16 S$ rDNA sequence determination and phylogenetic analyses. The extraction of genomic DNA, PCR amplification of the $16 \mathrm{~S} \mathrm{rDNA}$, and sequencing of the purified PCR products were carried out as described previously (22). Sequence reaction products were purified by ethanol precipitation and electrophoresed with a model 373A DNA sequencer (Applied Biosystems, Foster City, Calif.). The 16S rDNA sequences obtained in this study were aligned against the previously determined Meiothermus/Thermus sequences available from the public databases with the ae2 editor (16). The method of Jukes and Cantor (12) was used to calculate evolutionary distances. Phylogenetic dendrograms were generated with various treeing algorithms contained in the PHYLIP package $(6,7)$.

Nucleotide sequence accession number. The 16S rDNA sequences determined in this study have been deposited with EMBL under the following accession numbers: strain GY-1 ${ }^{\mathrm{T}}$, Y13594; strain GY-5, Y13595; strain GY-8, Y13598; strain GY-10, Y13599; strain 16105, Y13596; and strain 16106, Y13597. The accession numbers and strain designations of the $16 \mathrm{~S}$ rDNA reference sequences used in the phylogenetic analyses are as follows: Meiothermus chliarophilus DSM 9957 ${ }^{\mathrm{T}}$, X84212; Meiothermus silvanus DSM 9946 ${ }^{\mathrm{T}}$, X84211; Meiothermus ruber ATCC 35948 ${ }^{\mathrm{T}}$, L09678; Thermus aquaticus ATCC 25104 ${ }^{\mathrm{T}}$, L09663; Thermus filiformis ATCC $43280^{\mathrm{T}}$, L09667; Thermus thermophilus ATCC $27634^{\mathrm{T}}$, M26923; strain ac-2, L37521; and strain ac-17, L37523.

\section{RESULTS}

Isolation of strains, growth, and biochemical characteristics. The isolates designated GY originated from hot spring runoffs with temperatures ranging from about 50 to $70^{\circ} \mathrm{C}$ and $\mathrm{pHs}$ of about 9 in the Geysir area of Iceland. Red-orangepigmented colonies appeared on the surface of the membrane filters within 3 days of incubation. Growth on Thermus agar plates appeared normal, but these organisms did not grow or grew very poorly in the corresponding liquid medium, indicating that unknown components of the agar were necessary for the growth of these organisms. An autoclaved water extract of agar $\left(20 \mathrm{~g} \mathrm{liter}^{-1}\right)$ did not improve the growth of the organisms in liquid medium. Some metals added to the original Thermus medium, such as aluminum sulfate, vanadium chloride, nickel chloride, and sodium selenite in the range of 0.03 to $3.0 \mathrm{mg}$ liter $^{-1}$, had no effect on the growth of these strains. Yeast extract at concentrations ranging between 0.5 and $10 \mathrm{~g} \mathrm{liter}^{-1}$

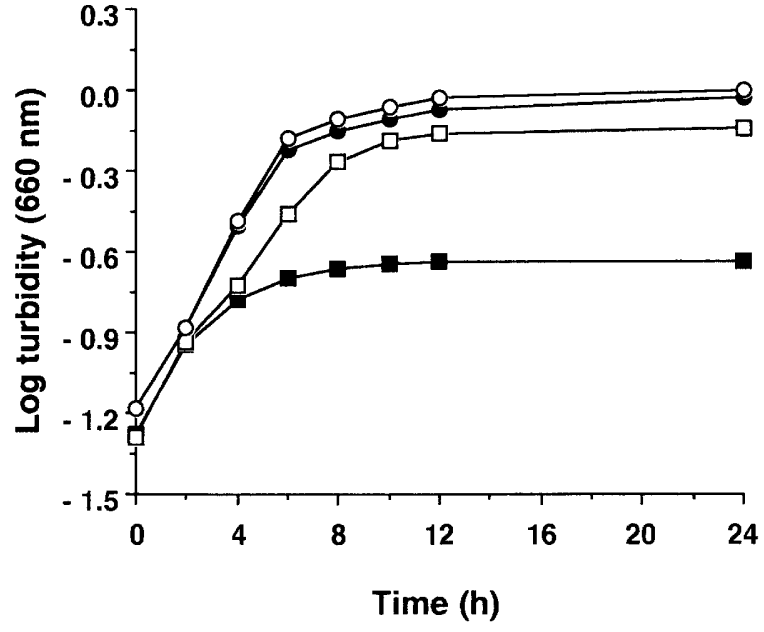

FIG. 1. Growth curves of strain GY-1 ${ }^{\mathrm{T}}$ in Thermus medium without the addition of reduced sulfur compounds $(\square)$ and in the presence of $0.1 \mathrm{~g}$ of cysteine liter ${ }^{-1}(\square), 0.1 \mathrm{~g}$ of thiosulfate $\operatorname{liter}^{-1}(\bullet)$, and $0.1 \mathrm{~g}$ of thioglycolate $\operatorname{liter}^{-1}(\mathrm{O})$.

did not improve the growth of these strains. However, the addition of cysteine $\left(0.1 \mathrm{~g} \mathrm{liter}^{-1}\right)$ greatly enhanced the growth of strains $\mathrm{GY}-1^{\mathrm{T}}$, GY-5, and GY-8. Sodium thiosulfate, in concentrations ranging between 0.1 and $5.0 \mathrm{~g} \mathrm{liter}^{-1}$, and sodium thioglycolate $\left(0.1 \mathrm{~g} \mathrm{liter}^{-1}\right)$ also improved the growth of these strains (Fig. 1), but none of these substances had a positive or negative effect on the growth of the type strain of Meiothermus ruber, $M$. ruber strains 16105 and 16106 isolated from Iceland, or the type strains of Meiothermus silvanus and Meiothermus chliarophilus. The addition of sodium glycolate to the medium at a concentration of $0.1 \mathrm{~g} \mathrm{liter}{ }^{-1}$ had no effect on the growth of any of the organisms. On the other hand, $\mathrm{Na}_{2} \mathrm{SO}_{3}\left(0.1 \mathrm{~g} \mathrm{liter}^{-1}\right)$ inhibited the growth of all the strains. Strain GY-10 only grew in liquid medium when ascorbate was added to a concentration of $1.0 \mathrm{~g} \mathrm{liter}^{-1}$. In view of these results, thiosulfate, at a concentration of $0.1 \mathrm{~g} \mathrm{liter}^{-1}$, was subsequently added to all of the media used for the growth of the strains examined in this study.

The cultures of strains GY $-1^{\mathrm{T}}$ and GY -5 were composed of long rods and filaments that stained gram negative; motility and spores were not observed. The optimum growth temperature of the new species was about $55^{\circ} \mathrm{C}$, and the optimum $\mathrm{pH}$ for growth was about 7.5 (Fig. 2). Strains GY-1 ${ }^{\mathrm{T}}$ and GY-5 produced red-orange colonies, like other strains of species of Meiothermus, except for Meiothermus chliarophilus, which produces yellow colonies. Strains GY $-1^{\mathrm{T}}$ and GY-5 were catalase negative like Meiothermus silvanus and Meiothermus chliarophilus (Table 1). The major differences in biochemical characteristics were found in the assimilation of single carbon sources; strains GY $-1^{\mathbf{T}}$ and GY -5 assimilated a lower number of single carbon sources tested than the type strains of the other species. For example, xylose, asparagine, glutamine, serine, and arginine were not used as a single carbon source by the strains of the new species, but they were assimilated by the strains of the other species (Table 1).

Thiosulfate utilization in the type strain of $M$. ruber and strain GY-5 was examined with Thermus medium lacking sulfate. Thiosulfate, at an initial concentration of $1.0 \mathrm{~g} \mathrm{liter}^{-1}$, became undetectable as the cultures of $M$. ruber reached the stationary phase of growth, with a concomitant increase in the levels of sulfate that, nevertheless, only reached about half of 

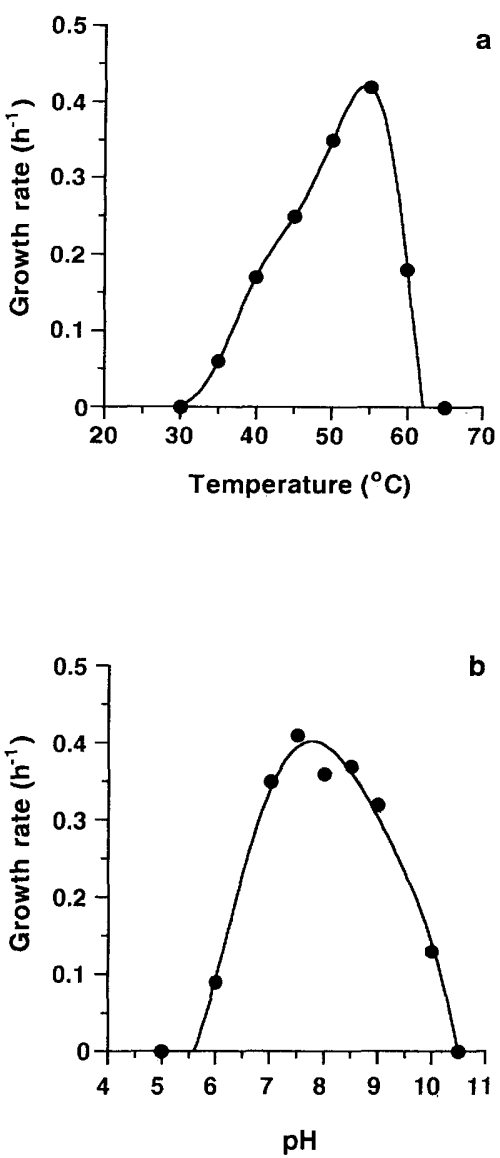

$1^{\mathrm{T}}$

FIG. 2. Effects of temperature (a) and pH (b) on the growth of strain GY-

the thiosulfate consumed (Fig. 3). For cultures of $M$. ruber, thiosulfate was only slightly oxidized when $0.1 \mathrm{~g} \mathrm{liter}^{-1}$ was added to the medium. Sulfur crystals were not observed by phase-contrast microscopy in the medium or associated with the cells of $M$. ruber. For strain GY-5, the levels of thiosulfate did not decrease, nor was the formation of sulfate detected, even though the final turbidity was very similar to that reached by $M$. ruber (results not shown).

Polar lipids, respiratory quinones, and fatty acids. The polar lipids of all strains consisted of one major phospholipid and two prominent glycolipids, designated glycolipids $1 \mathrm{a}$ and $1 \mathrm{~b}$, migrating close to each other near the origin (Fig. 4). Minor glycolipids and phospholipids were not generally present in most of the strains. Menaquinone 8 was the only respiratory lipoquinone detected in all strains.

The major fatty acids of all organisms examined in this study were iso and anteiso branched (Table 2). The fatty acid composition of strains GY-8 and GY-10 from Geysir, Iceland, was practically identical to that of the type strain of Meiothermus silvanus. In these strains, the relative proportion of 15:0 anteiso fatty acid was higher than that of 15:0 iso fatty acid, while in all of the other strains, 15:0 anteiso fatty acid was present in lower levels than 15:0 iso fatty acid. Two red-pigmented strains isolated previously from Iceland, but not assigned to any of the species of the genus Meiothermus, had fatty acid compositions that were very similar to those of the type strain of $M$. ruber. However, strains GY $-1^{\mathrm{T}}$ to GY -6 could be distinguished from the other strains by the larger relative proportions of $3-\mathrm{OH}$ fatty acids than 2-OH fatty acids in cells grown in Thermus agar lacking thiosulfate. It is interesting that large alterations in the fatty acid composition were observed when the GY strains were grown in medium containing thiosulfate. These alterations included the production of larger amounts of $2-\mathrm{OH}$ fatty acids and smaller, but still significant, amounts of 3-OH fatty acids (Table 2). On the other hand, the fatty acid compositions of Meiothermus chliarophilus, Meiothermus ruber, and Meiothermus silvanus strains were identical in cells derived from growth in Thermus agar with or without thiosulfate.

$16 S$ rDNA sequence analysis, $G+C$ content, and DNA reassociation. Full $16 \mathrm{~S}$ rDNA sequences 1,436 (strains $\mathrm{GY}-1^{\mathrm{T}}$, GY-5, 16105, and 16106) or 1,440 (strains GY-8 and GY-10) nucleotides in length were determined. An initial comparison of the $16 \mathrm{~S}$ rDNA sequence determined in this study with representatives of the main bacterial lines of descent indicated that these strains fell within the radiation of the Meiothermus/ Thermus lineage. A more detailed analysis based on a data set comprising 1,400 unambiguous nucleotides between positions 28 and 1526 (Escherichia coli positions [1]) showed the new isolates to be most closely related to the genus Meiothermus (Fig. 5). On the basis of 16S rDNA sequence comparison, the six strains for which $16 \mathrm{~S}$ rDNA sequences were determined comprise three pairs. Strains GY-8 and GY-10, which have identical 16S rDNA sequences over all positions determined, cluster with Meiothermus silvanus, to which they have $99.9 \%$ $16 \mathrm{~S}$ rDNA sequence similarity (Fig. 5). The $16 \mathrm{~S}$ rDNA sequences of strains 16105 and 16106, also isolated from Iceland,

TABLE 1. Phenotypic characteristics that distinguish strains of the genus Meiothermus ${ }^{a}$

\begin{tabular}{|c|c|c|c|c|c|}
\hline Characteristic & $\mathrm{GY}-1^{b}$ & GY -5 & $\begin{array}{c}M . \\
\text { ruber }^{b}\end{array}$ & $\begin{array}{c}M . \\
\text { silvanus }^{b}\end{array}$ & $\begin{array}{c}M . \\
\text { chliarophilus }^{b}\end{array}$ \\
\hline Pigmentation & Red & Orange & Red & Red & Yellow \\
\hline \multicolumn{6}{|l|}{ Presence of: } \\
\hline Catalase & - & - & + & - & - \\
\hline$\alpha$-Galactosidase & + & + & + & - & + \\
\hline \multicolumn{6}{|l|}{ Hydrolysis of: } \\
\hline Elastin & + & + & + & - & + \\
\hline Starch & - & - & - & - & + \\
\hline Esculin & + & + & + & - & + \\
\hline Reduction of nitrate & - & - & - & + & + \\
\hline \multicolumn{6}{|l|}{ Utilization of: } \\
\hline D-Cellobiose & + & + & + & - & + \\
\hline D-Raffinose & - & - & + & - & + \\
\hline D-Mannitol & - & - & + & - & + \\
\hline D-Sorbitol & - & - & + & - & + \\
\hline D-Xylose & - & - & + & + & + \\
\hline D-Trehalose & + & + & + & - & + \\
\hline Glycerol & - & - & + & - & + \\
\hline Pyruvate & + & + & - & + & + \\
\hline Succinate & - & - & + & - & - \\
\hline Malate & - & - & + & - & - \\
\hline myo-Inositol & - & - & + & - & + \\
\hline L-Asparagine & - & - & + & + & + \\
\hline L-Glutamine & - & - & + & + & + \\
\hline L-Serine & - & - & + & + & + \\
\hline L-Proline & + & + & + & - & + \\
\hline L-Arginine & - & - & + & + & + \\
\hline
\end{tabular}

${ }^{a} M$. chliarophilus was grown at $50^{\circ} \mathrm{C}$; the other strains were grown at $55^{\circ} \mathrm{C}$. + , positive result or growth; -, negative result or no growth. All of the organisms hydrolyzed DNA, fibrin, casein, gelatin, and hide powder azure; degraded arbutin; and were $\beta$-galactosidase positive. D-Glucose, D-fructose, D-mannose, Dgalactose, D-melibiose, maltose, lactose, sucrose, and L-glutamate were utilized by all of the strains. None of the strains hydrolyzed xylan or utilized L-arabinose, L-rhamnose, citrate, and ribitol.

${ }^{b}$ Type strain used. 


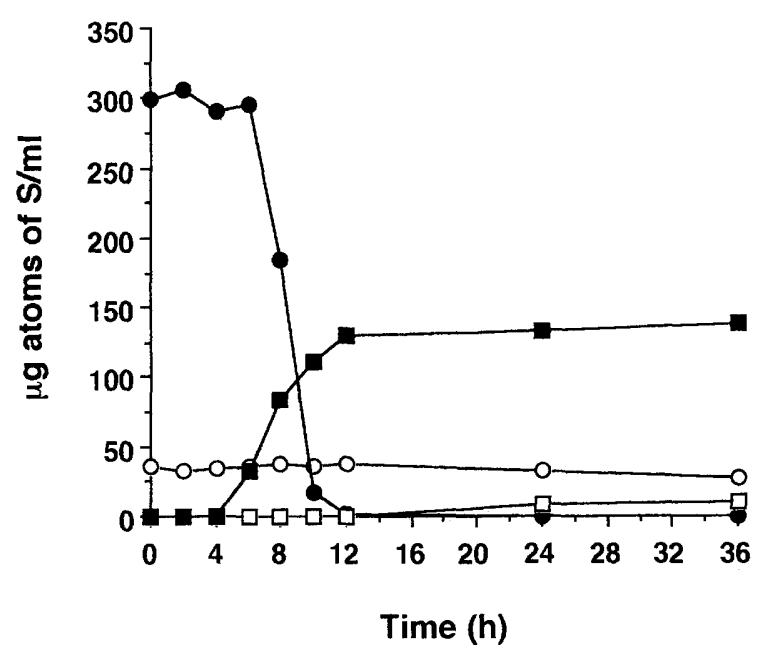

FIG. 3. Utilization of thiosulfate and formation of sulfate by the type strain of $M$. niber. Solid symbols, utilization of thiosulfate $(-$ and formation of sulfate (ם) when thiosulfate was added to the medium at an initial concentration of $1.0 \mathrm{~g}$ liter $^{-1}$; open symbols, utilization of thiosulfate $(O)$ and formation of sulfate $(\square)$ when thiosulfate was added to the medium at an initial concentration of $0.1 \mathrm{~g}$ liter ${ }^{-1}$.

were found to be identical to that previously determined for the type strain of the species Meiothermus ruber (Fig. 5). The third pair of strains, GY-1 ${ }^{\mathrm{T}}$ and GY-5, had identical $16 \mathrm{~S}$ rDNA sequences and showed the highest similarity to the $16 \mathrm{~S}$ rDNA sequences of strains ac-2 and ac-17 (99.6 and 99.7\%, respectively) previously determined by Nold and Ward (21). These strains formed a sister cluster next to that of the type strain of Meiothermus ruber and strains 16105 and 16106 (Fig. 5). The level of $16 \mathrm{~S}$ rDNA sequence similarity between the GY-1GY-5 cluster and the Meiothermus ruber cluster was in the range of 98.3 to $98.6 \%$. The $16 \mathrm{~S}$ rDNA sequence similarity of strains $\mathrm{GY}-1^{\mathrm{T}}$ and $\mathrm{GY}-5$ to the other species of the genus Meiothermus was lower, ranging from $88.8 \%$ with $M$. silvanus to $90.3 \%$ with $M$. chliarophilus. The $\mathrm{G}+\mathrm{C}$ content of $\mathrm{GY}-1^{\mathrm{T}}$ was $60.9 \mathrm{~mol} \%$, while the distinct species status of strain GY-1 was demonstrated by a DNA-DNA reassociation value of $50.2 \%$ with the type strain of $M$. ruber (results not shown).

\section{DISCUSSION}

The results of $16 \mathrm{~S}$ rDNA sequence analysis show the new isolates to be members of the genus Meiothermus; strains GY-8 and GY-10 have very high similarity to Meiothermus silvanus, while strains 16105 and 16106 have the same $16 \mathrm{~S}$ rDNA sequence as Meiothermus ruber. Strains GY-1 ${ }^{\mathrm{T}}$ and GY-5 cluster with, but separate from, Meiothermus ruber by $16 \mathrm{~S}$ rDNA sequence similarity; DNA-DNA reassociation studies show that strains $\mathrm{GY}-1^{\mathrm{T}}$ and $\mathrm{GY}-5$ represent a distinct species from Meiothermus ruber. The high degree of $16 \mathrm{~S}$ rDNA sequence similarity between strains GY-1 ${ }^{\mathrm{T}}$ and $\mathrm{GY}-5$ and strains ac-2 and ac- 17 could indicate that they are all strains of the one species found in Iceland and Yellowstone National Park.

The presence of 2-OH fatty acids in moderate relative proportions, ranging between about 10 and $13 \%$, is a chemotaxonomic characteristic of all of the strains of the species of the genus Meiothermus examined to date, while 3-OH fatty acids are minor or trace components of these organisms when grown on Thermus agar plates and do not exceed $1.5 \%$. On the other hand, $2-\mathrm{OH}$ fatty acids are not detected in the species of the genus Thermus, and $3-\mathrm{OH}$ fatty acids are restricted to the majority of the strains of Thermus aquaticus and to Thermus filiformis WAI33 $\mathrm{A}^{\mathrm{T}}$, in which they are exclusively linked to galactosamine in the major glycolipid $(2,20)$. The species represented by strains $\mathrm{GY}-1^{\mathrm{T}}$ and $\mathrm{GY}-5$ have lower levels of $2-\mathrm{OH}$ fatty acids in Thermus agar medium lacking thiosulfate than those of the strains of the other species of the genus Meiothermus, and higher levels of 3-OH fatty acids. However, larger amounts of 2-OH fatty acids are present when the strains of the new species are derived from Thermus agar containing thiosulfate, although the levels of 3-OH fatty acids remain high compared to those of the strains of the other species of this genus. The presence of higher levels of $3-\mathrm{OH}$ fatty acids in these strains appears to be useful in distinguishing this species from other species of this genus, while the presence of $2-\mathrm{OH}$ fatty acids corroborates the assignment of the strains to a species belonging to the genus Meiothermus. The identical fatty acid compositions of the isolates of Meiothermus silvanus, from geographically distant hot springs at Vizela in Portugal and Geysir in Iceland, in addition to their extremely high $16 \mathrm{~S}$ rDNA sequence similarities reinforces the usefulness of this chemotaxonomic parameter in distinguishing the species of this genus (20). The strains of the new species also had polar lipid patterns similar to those of the other species of the genus Meiothermus, consisting of one major polar lipid and two prominent glycolipids migrating close to the origin (29).

The requirement for reduced sulfur compounds by strains GY $-1^{\mathrm{T}}$ and GY-5 has not been investigated in detail. Sulfate is not produced by strains GY-1 ${ }^{\mathrm{T}}$ and GY-5 during growth in medium containing thiosulfate. Moreover, the inability to detect thiosulfate utilization by strain GY-5 may be due to the small amounts used by the strain for growth, leading to the hypothesis that the strains of the new species cannot reduce sulfate by the assimilatory sulfate reduction pathway. These thiosulfate-requiring strains may not be able to take up or reduce the sulfate present in the medium, and the cysteine contained in tryptone may not be sufficient to promote good growth or may be destroyed during sterilization. On the other hand, the type strain of $M$. ruber is capable of oxidizing thiosulfate to sulfate, although this strain shows no requirement for reduced sulfur compounds and growth is not improved by their addition to the growth medium. This is the first report of the oxidation of thiosulfate to sulfate by a strain of the genus Meiothermus and may be analogous to the so-called gratuitous oxidation of sulfur compounds found in other heterotrophic bacteria $(4,26)$. However, about half of the thiosulfate utilized by this bacterium was not accounted for in the form of sulfate, although this was not investigated further.

In our view, the requirement of reduced sulfur compounds by strains $\mathrm{GY}-1^{\mathrm{T}}$ and GY-5 is not a valid taxonomic charac-

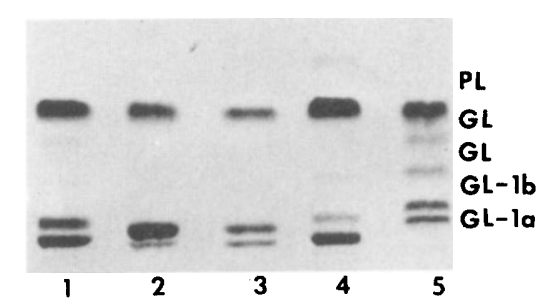

FIG. 4. Single-dimension thin-layer chromatography of polar lipids of Meiothermus strains. Components were revealed by staining the TLC plates with $5 \%$ molybdophosphoric acid in ethanol and heating them at $160^{\circ} \mathrm{C}$. Lanes: $1, M$. ruber (DSM $1279^{\mathrm{T}}$ ); 2, strain GY-1 ${ }^{\mathrm{T}}$; 3, strain GY-8; 4, M. silvanus (DSM 9946 ${ }^{\mathrm{T}}$ ); 5, M. chliarophilus (DSM 9957 ${ }^{\mathrm{T}}$ ). PL, phospholipid; GL-1a, glycolipid-1a; GL-1b, glycolipid-1b; GL, minor glycolipid. 
TABLE 2. Mean fatty acid composition of the strains examined after growth at $50^{\circ} \mathrm{C}$

\begin{tabular}{|c|c|c|c|c|c|c|c|c|}
\hline \multirow{3}{*}{ Fatty acid ${ }^{a}$} & \multicolumn{8}{|c|}{$\%$ of fatty acid in: } \\
\hline & \multicolumn{2}{|c|}{ GY-1-GY-6 $(n=6)^{b}$} & \multicolumn{2}{|c|}{ M. ruber $(n=3)$} & \multicolumn{2}{|c|}{ M. silvanus $(n=5)$} & \multicolumn{2}{|c|}{ M. chliarophilus $(n=1)$} \\
\hline & $+\mathrm{S}_{2} \mathrm{O}_{3}{ }^{2-}$ & $-\mathrm{S}_{2} \mathrm{O}_{3}{ }^{2-}$ & $+\mathrm{S}_{2} \mathrm{O}_{3}{ }^{2-}$ & $-\mathrm{S}_{2} \mathrm{O}_{3}{ }^{2-}$ & $+\mathrm{S}_{2} \mathrm{O}_{3}{ }^{2-}$ & $-\mathrm{S}_{2} \mathrm{O}_{3}{ }^{2-}$ & $+\mathrm{S}_{2} \mathrm{O}_{3}{ }^{2-}$ & $-\mathrm{S}_{2} \mathrm{O}_{3}{ }^{2-}$ \\
\hline $13: 0$ iso & & 1.4 & & & & & 1.3 & 1.5 \\
\hline $14: 0$ iso & 2.1 & 2.7 & & & & & 1.7 & 2.0 \\
\hline 13:0 iso-3-OH & & & & & 1.5 & 1.6 & & \\
\hline $15: 1$ iso- $F^{c}$ & 3.7 & 3.8 & 2.2 & 2.2 & & & & \\
\hline $15: 0$ iso & 31.4 & 34.6 & 33.7 & 31.9 & 24.7 & 24.1 & 40.2 & 40.7 \\
\hline 15:0 anteiso & 5.1 & 11.1 & 4.2 & 5.2 & 29.6 & 30.4 & 7.8 & 9.3 \\
\hline 15:0 & 1.9 & 1.6 & 2.0 & 1.8 & & & 2.1 & 2.3 \\
\hline $16: 1 \omega 7 \mathrm{t}$ alcohol & 2.4 & 1.9 & & & & & & \\
\hline $16: 0$ iso & 4.9 & 4.0 & 2.7 & 3.1 & 1.4 & & 2.7 & 3.0 \\
\hline $16: 0$ & 5.1 & 4.5 & 5.7 & 5.5 & 5.3 & 4.9 & 8.2 & 7.6 \\
\hline Unknown $16.090^{d}$ & & & & & 2.1 & 2.1 & & \\
\hline $15: 0$ iso-3-OH & & & & & & & 1.4 & 1.5 \\
\hline iso $17: 1 \omega 9 \mathrm{c}$ & 8.0 & 4.8 & 6.6 & 6.4 & & & & \\
\hline $17: 0$ iso & 9.6 & 5.8 & 17.4 & 16.5 & 11.1 & 10.6 & 17.0 & 15.2 \\
\hline $17: 0$ anteiso & 2.0 & 2.5 & 3.4 & 4.0 & 6.8 & 7.1 & 2.7 & 3.0 \\
\hline $17: 1 \omega 8 \mathrm{c}$ & 1.1 & & & & & & & \\
\hline $17: 1 \omega 6 c$ & & & & & & & 1.1 & \\
\hline $17: 0$ & & & 1.2 & 2.2 & & & 1.6 & 1.2 \\
\hline $17: 0$ iso- $2-\mathrm{OH}$ & 6.3 & 3.3 & 9.1 & 8.9 & 8.4 & 8.5 & 9.0 & 8.1 \\
\hline 17:0 anteiso-2-OH & & & & & 2.8 & 3.0 & & \\
\hline 17:0 iso-3-OH & 3.9 & 4.7 & 1.5 & 1.6 & & & & \\
\hline $17: 0$ anteiso-3-OH & & 1.4 & & & & & & \\
\hline $19: 0$ iso & & & & & 2.0 & 1.7 & & \\
\hline 19:0 anteiso & & & & & 1.6 & 1.4 & & \\
\hline Unknown $19.060^{d}$ & & & & & 1.8 & 2.0 & & \\
\hline
\end{tabular}

${ }^{a}$ Data for several fatty acids that were present at levels of less than $1.0 \%$ in all strains are not shown.

${ }^{b} n$, number of strains examined.

${ }^{c}$ The double-bond position of this fatty acid is not known.

${ }^{d}$ Unknown fatty acid or alcohol with equivalent chain lengths of 16.090 and 19.060 , respectively.

teristic of the new species, because strain GY-8, which shares a very high $16 \mathrm{~S}$ rDNA similarity with the type strain of Meiothermus silvanus, has the same requirement, while strain GY10, which also appears to belong to Meiothermus silvanus on the basis of $16 \mathrm{~S}$ rDNA sequence analysis and fatty acid composition, has a requirement for ascorbate. Neither of these requirements was found in the strains of this species isolated from Vizela (29) nor in any other known isolate of the genus Meiothermus or Thermus $(9,13,19,33)$. Likewise, stimulation of the growth of strains ac-2 and ac-17 from Yellowstone National Park by reduced sulfur compounds was not reported, even though these strains are clearly closely related to the strains of the new species on the basis of $16 \mathrm{~S}$ rDNA sequence similarity (21).

Strains of the genus Meiothermus with these requirements have never been isolated before, probably because, in many cases, liquid enrichments of the samples selected against organisms requiring reduced sulfur compounds or ascorbate or because they are not found in the springs examined previously. Nevertheless, we generally use filtration methods identical to the ones used in this study, which allow the isolation of a large variety of colony types, and have never encountered red-orange-pigmented strains with these requirements (29).

Differences in carbon source assimilations, the distinctive fatty acid composition with high proportions of $3-\mathrm{OH}$ fatty acids, the low DNA-DNA hybridization values with Meiothermus ruber, and the 16S rRNA divergence lead us to propose the species Meiothermus cerbereus for strains GY-1 ${ }^{\mathrm{T}}$ and GY-5.

Description of Meiothermus cerbereus sp. nov. Meiothermus cerbereus (cer.be.re'us. L. adj. cerbereus, the monstrous dog Cerberus that guarded the mythological Greek Hades, so named because of the difficulty we had in growing the strains of this species in liquid medium).

Meiothermus cerbereus strains have rod-shaped cells of variable length which are 0.5 to 0.8 (strains GY-1 ${ }^{\mathrm{T}}$ and GY-5) $\mu \mathrm{m}$ wide. Long filaments are also present. Gram stain is negative.

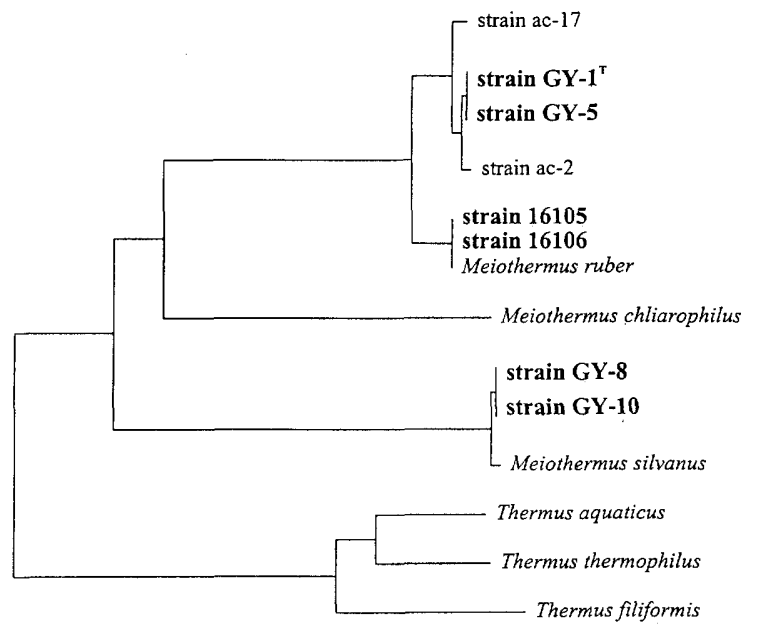

$5 \%$

FIG. 5. 16S rDNA-based phylogenetic dendrogram reconstructed from evolutionary distances (12) by the neighbor-joining method (24). The scale bar represents 5 inferred nucleotide substitutions per 100 nucleotides. 
The cells are nonmotile, and spores are not formed. Colonies on Thermus medium with and without sodium thiosulfate are red-orange pigmented and 1 to $2 \mathrm{~mm}$ in diameter after $72 \mathrm{~h}$ of growth. Cysteine, thiosulfate, or thioglycolate is required for growth of strains GY $-1^{\mathbf{T}}$ and GY -5 in liquid medium. Growth occurs between 35 and $60^{\circ} \mathrm{C}$; the optimum growth temperature for strain $\mathrm{GY}-1^{\mathrm{T}}$ is about $55^{\circ} \mathrm{C}$. The optimum $\mathrm{pH}$ is about 7.5 ; growth does not occur at $\mathrm{pH} 5.0$ or 10.5 . The major fatty acids are 15:0 iso and 15:0 anteiso and 17:0 iso and 17:0 anteiso; $3-\mathrm{OH}$ fatty acids are present in higher levels than $2-\mathrm{OH}$ fatty acids when strains are grown in Thermus agar without thiosulfate. All strains are oxidase positive and catalase negative. Nitrate is not reduced to nitrite. $\alpha$ - and $\beta$-galactosidase positive. Elastin, fibrin, casein, and hide powder azure are hydrolyzed. Degradation of arbutin and esculin is positive. Strains GY $-1^{\mathrm{T}}$ and GY-5 utilize D-glucose, D-fructose, D-mannose, Dgalactose, D-melibiose, D-cellobiose, D-trehalose, maltose, lactose, sucrose, pyruvate, L-glutamate, and L-proline. Strains GY $-1^{\mathrm{T}}$ and GY-5 do not hydrolyze starch or utilize D-raffinose, D-mannitol, D-sorbitol, D-xylose, glycerol, ribitol, succinate, malate, citrate, myo-inositol, L-asparagine, L-serine, L-glutamine, L-arabinose, L-rhamnose, and $\mathrm{L}$-arginine.

The DNA of strain GY-1 ${ }^{\mathrm{T}}$ has a $\mathrm{G}+\mathrm{C}$ content of $60.9 \mathrm{~mol} \%$. This bacterium was isolated from hot springs in the Geysir area of Iceland. Strain GY $-1^{\mathrm{T}}$ has been deposited in the Deutsche Sammlung von Mikroorganismen und Zellkulturen, Braunschweig, Germany, as strain DSM 11376. Strain GY-5 (DSM 11377 ) is a reference strain of this species.

\section{ACKNOWLEDGMENTS}

This work was supported in part by the European Community Biotech Programme (Biotechnology of Extremophiles), contract no. BIO2-CT93-0274, and the PRAXIS XXI Program (PRAXIS 2/2.1/ BIO/20/94), Portugal. A.P.C. was supported by a PRAXIS XXI scholarship (PRAXIS XXI/BD/3907/94).

We also thank Hans Trüper (University of Bonn, Bonn, Germany) for advice in naming this organism and many helpful suggestions.

\section{REFERENCES}

1. Brosius, J., M. L. Palmer, P. J. Kennedy, and H. F. Noller. 1978. Complete nucleotide sequence of a 16S ribosomal RNA gene from Escherichia coli. Proc. Natl. Acad. Sci. USA 75:4801-4805.

2. Carreto, L., R. Wait, M. F. Nobre, and M. S. da Costa. 1996. Determination of the structure of a novel glycolipid from Thermus aquaticus 15004 and demonstration that hydroxy fatty acids are amide linked to glycolipids in Thermus spp. J. Bacteriol. 178:6479-6486.

3. Cashion, P., M. A. Holder-Franklin, J. McCully, and M. Franklin. 1987. A rapid method for the base ratio determination of bacterial DNA. Anal. Biochem. 81:461-466.

4. Das, S. K., A. K. Mishra, B. J. Tindall, F. A. Rainey, and E. Stackebrandt. 1996. Oxidation of thiosulfate by a new bacterium, Bosea thiooxidans (strain BI-42) gen. nov., sp. nov.: analysis of phylogeny based on chemotaxonomy and 16S ribosomal DNA sequencing. Int. J. Syst. Bacteriol. 46:981-987.

5. De Ley, J., H. Cattoir, and A. Reynaerts. 1970. The quantitative measurement of DNA hybridization from renaturation rates. Eur. J. Biochem. 12: 133-142.

6. De Soete, G. 1983. A least squares algorithm for fitting additive trees to proximity data. Psychometrika 48:621-626.

7. Felsenstein, J. 1993. PHYLIP (phylogenetic inference package) version 3.5.1. Department of Genetics, University of Washington, Seattle.

8. Hensel, R., W. Demharter, O. Kandler, R. M. Kroppenstedt, and E. Stackebrandt. 1986. Chemotaxonomic and molecular-genetic studies of the genus Thermus: evidence for a phylogenetic relationship of Thermus aquaticus and Thermus ruber to the genus Deinococcus. Int. J. Syst. Bacteriol. 36:444-453.

9. Hudson, J. A., H. W. Morgan, and R. M. Daniel. 1989. Numerical classifi- cation of Thermus isolates from globally distributed hot springs. Syst. Appl. Microbiol. 11:250-256.

10. Huß, V. A. R., H. Festl, and K. H. Schleifer. 1983. Studies on the spectrophotometric determination of DNA hybridization from renaturation rates. Syst. Appl. Microbiol. 4:184-192.

11. Janke, K. D. 1992. BASIC computer program for evaluation of spectroscopic DNA renaturation data from GILFORD SYSTEM 2600 spectrophotometer on a PC/XT/AT type personal computer. J. Microbiol. Methods 15:61-73.

12. Jukes, T. H., and C. R. Cantor. 1969. Evolution of protein molecules, p. 21-132. In H. N. Munro (ed.), Mammalian protein metabolism. Academic Press, New York, N.Y.

13. Kristjansson, J. K., S. Hjörleifsdottir, V. T. Marteinsson, and G. A. Alfredsson. 1994. Thermus scotoductus, sp. nov., a pigment-producing thermophilic bacterium from hot tap water in Iceland and including Thermus sp. X-1. Syst. Appl. Microbiol. 17:44-50.

14. Kuykendall, L. D., M. A. Roy, J. J. O'Neill, and T. E. Devine. 1988. Fatty acids, antibiotic resistance, and deoxyribonucleic acid homology groups of Bradyrhizobium japonicum. Int. J. Syst. Bacteriol. 38:358-361.

15. Loginova, L. G., L. A. Egorova, R. S. Golovacheva, and L. M. Seregina. 1984. Thermus ruber sp. nov., nom. rev. Int. J. Syst. Bacteriol. 34:498-499.

16. Maidak, B. L., N. Larsen, M. J. McCaughey, R. Overbeek, G. J. Olsen, K. Fogel, J. Blandy, and C. R. Woese. 1994. The Ribosomal Database Project. Nucleic Acids Res. 22:3485-3487.

17. Manaia, C. M., and M. S. da Costa. 1991. Characterization of halotolerant Thermus isolates from shallow marine hot springs on S. Miguel, Azores. J. Gen. Microbiol. 137:2643-2648.

18. Mesbah, M., U. Premachandran, and W. B. Whitman. 1989. Precise measurement of the $\mathrm{G}+\mathrm{C}$ content of deoxyribonucleic acid by high-performance liquid chromatography. Int. J. Syst. Bacteriol. 39:159-167.

19. Nobre, M. F., H. G. Trüper, and M. S. da Costa. 1996. Transfer of Thermus nuber (Loginova et al. 1984), Thermus silvanus (Tenreiro et al. 1995), and Thermus chliarophilus (Tenreiro et al. 1995) to Meiothermus gen. nov. as Meiothermus ruber comb. nov., Meiothermus silvanus comb. nov., and Meiothermus chliarophilus comb. nov., respectively, and emendation of the genus Thermus. Int. J. Syst. Bacteriol. 46:604-606.

20. Nobre, M. F., L. Carreto, R. Wait, S. Tenreiro, O. Fernandes, R. J. Sharp, and M. S. da Costa. 1996. Fatty acid composition of the species of the genera Thermus and Meiothermus. Syst. Appl. Microbiol. 19:303-311.

21. Nold, S. C., and D. M. Ward. 1995. Diverse Thermus species inhabit a single hot spring microbial mat. Syst. Appl. Microbiol. 18:274-278.

22. Rainey, F. A., N. Ward-Rainey, R. M. Kroppenstedt, and E. Stackebrandt. 1996. The genus Nocardiopsis represents a phylogenetically coherent taxon and a distinct actinomycete lineage: proposal of Nocardiopsaceae fam. nov. Int. J. Syst. Bacteriol. 46:1088-1092.

23. Ruffett, M., S. Hammond, R. A. D. Williams, and R. J. Sharp. 1992. A taxonomic study of red pigmented gram negative thermophiles, p. 74. In A. M. Geirsdöttir, H. P. Brown, and T. Skjenstad (ed.), Conference Program Abstracts. Thermophiles: Science and Technology. IceTec, Reykjavik, Iceland.

24. Saitou, N., and M. Nei. 1987. The neighbor-joining method: a new method for reconstructing phylogenetic trees. Mol. Biol. Evol. 4:406-425.

25. Santos, M. A., R. A. D. Williams, and M. S. da Costa. 1989. Numerical taxonomy of Thermus isolates from hot springs in Portugal. Syst. Appl. Microbiol. 12:310-315.

26. Schook, L. B., and R. S. Berk. 1978. Nutritional studies with Pseudomonas aeruginosa grown on inorganic sulfur sources. J. Bacteriol. 133:1377-1382.

27. Sharp, R. J., and R. A. D. Williams. 1988. Properties of Thermus ruber strains isolated from Icelandic hot springs and DNA:DNA homology of Thermus ruber and Thermus aquaticus. Appl. Environ. Microbiol. 54:2049-2053.

28. Sörbo, B. 1987. Sulfate: turbidimetric and nephelometric methods. Methods Enzymol. 143:3-6.

29. Tenreiro, S., M. F. Nobre, and M. S. da Costa. 1995. Thermus silvanus sp. nov. and Thermus chliarophilus sp. nov., two new species related to Thermus ruber but with lower growth temperatures. Int. J. Syst. Bacteriol. 45:633-639.

30. Tindall, B. J. 1989. Fully saturated menaquinones in the archaebacterium Pyrobaculum islandicum. FEMS Microbiol. Lett. 60:251-254.

31. Tindall, B. J. 1991. Lipid composition of Rhodothermus marinus. FEMS Microbiol. Lett. 80:65-68.

32. Westley, J. 1987. Thiocyanate and thiosulfate. Methods Enzymol. 143:23-25.

33. Williams, R. A. D., and M. S. da Costa. 1992. The genus Thermus and related microorganisms, p. 3745-3753. In A. Balows, H. G. Trüper, M. Dworkin. W. Harder, and K. H. Schleifer (ed.), The prokaryotes, 2nd ed. Springer-Verlag, New York, N.Y. 